\title{
REFORMA DO ENSINO MÉDIO (LEI № 13.415/2017): RETROCESSO NO ENSINO MÉDIO PROPEDÊUTICO E TÉCNICO-PROFISSIONALIZANTE
}

\author{
Italan Carneiro* \\ *E-mail: italancarneiro@gmail.com \\ Instituto Federal de Educação, Ciência e Tecnologia da Paraíba, João Pessoa, Brasil \\ DOI: $10.15628 /$ rbept.2020.8121
}

Artigo submetido em dez/2018 e aceito em fev/2020

\begin{abstract}
RESUMO
Neste texto, abordamos a recente reforma do Ensino Médio iniciada através da Medida Provisória 746/2016. Partimos da compreensão que o Ensino Médio historicamente apresenta-se no cenário educacional brasileiro como palco de disputas sociais e políticas nas quais os projetos de sociedade dos setores produtivos e dos trabalhadores, via de regra antagônicos, entram em conflito. A partir de pesquisa documental e bibliográfica, compreendemos que a atual iniciativa apresenta um discurso oficial voltado à "modernização" do currículo do Ensino Médio, objetivando a redução (ou exclusão) de disciplinas que foram consideradas "desinteressantes" e/ou "inúteis", tais quais educação física, arte, geografia, história, sociologia e filosofia. Desse modo, confirmou-se uma proposta tecnicista voltada à flexibilização e precarização da formação ofertada ao longo do Ensino Médio.
\end{abstract}

Palavras-Chave: Ensino Médio. Tecnicismo. MP 746/2016. Lei 13.415/2017.

\section{SECONDARY EDUCATION REFORM (LAW NO 13.415 OF 2017): RETROGRADE STEP IN THE PROPAEDEUTIC AND TECHNICAL PROFESSIONAL SECONDARY EDUCATION}

\begin{abstract}
The aim of this work is to approach the recent reform of High School, which was initiated through the Provisional Measure 746 of 2016. This approach starts from the understanding that the High School historically presents itself as the stage of social and political disputes in the Brazilian educational scene, which makes that projects of society, productive sectors and workers, usually antagonistic, comes into conflict. From documentary and bibliographical research, the current initiative presents an official discourse directed towards "modernization" of the secondary education curriculum, aiming at reducing (or excluding) disciplines that were considered "uninteresting" or "useless" such as physical education, arts, geography, history, sociology and philosophy. Thereby actually, it was confirmed a technicist proposal aimed at relaxation and precariousness of the training offered throughout secondary education.
\end{abstract}

Keywords: Secondary Education; Technicism; PM 746/2016; Law 13.415/2017.

Keywords: Keywords: Secondary Education; Technicism; PM 746/2016; Law 13.415/2017. 


\section{INTRODUÇÃO}

Este trabalho apresenta recorte da pesquisa de doutorado intitulada: "XXX"1. O trabalho definiu como um dos seus objetivos a compreensão acerca da construção histórica da educação profissional no Brasil em suas inter-relações com o Ensino Médio propedêutico. Partindo de pesquisa documental e bibliográfica, abordamos nesse texto especificamente a recente reforma (ou contra-reforma, como veremos adiante) do Ensino Médio iniciada através da Medida Provisória 746 de 22 de setembro de 2016.

Iniciamos nossa reflexão com a ressalva que a elaboração, bem como a interpretação das propostas educacionais em todos os contextos configura um processo permeado por embates, pois, "como sabemos, a estrutura discursiva Educação, envolve múltiplos campos discursivos que têm intrínseca uma infinitude de demandas e particularidades que ocupam terrenos híbridos, disputados pelas diversas concepções de pessoa, sociedade, cultura, política e economia" (MEDEIROS; LEITE; PEREIRA, 2013 , p. 147). Nessa perspectiva, realizando análise acerca do desenvolvimento social e histórico da Educação Secundária que explicita claramente a correlação de forças antagônicas presentes na sociedade, os Parâmetros Curriculares Nacionais para o Ensino Médio (2000) apontam o Ensino Médio como recorrente palco de disputas acerca dos rumos educacionais do Brasil:

Pelo caráter que assumiu na história educacional de quase todos os países, a educação média é particularmente vulnerável à desigualdade social. Enquanto a finalidade do Ensino Fundamental nunca está em questão, no Ensino Médio se dá uma disputa permanente entre orientações mais profissionalizantes ou mais acadêmicas, entre objetivos humanistas e econômicos. Essa tensão de finalidades expressa-se em privilégios e exclusões quando, como ocorre no caso brasileiro, a origem social é o fator mais forte na determinação de quais têm acesso à educação média e à qual modalidade se destinam. (BRASIL, 2000, p. 54)

Desse modo, partindo da compreensão que o contexto educacional configura local de disputas visando a manutenção de determinado projeto de sociedade que atenda aos interesses de determinadas classes sociais, analisamos a recente proposta de "reforma" do Ensino Médio, advinda do governo do Presidente Michel Temer.

\footnotetext{
1 Pesquisa desenvolvida no Programa de Pós Graduação em XXX, subárea $X X X$, da Universidade Federal da XXX, sob a orientação do Prof. Dr. XXX. Disponível em: $<X X X>$. Acesso em: 10/08/2018.
} 


\section{MEDIDA PROVISÓRIA 746/2016}

Em 22 de setembro de 2016, passados apenas 22 dias da posse definitiva da gestão do governo Michel Temer e ainda diante de um processo conturbado marcado pela ausência de legitimidade (tendo em vista que diversas análises compreenderam o impeachment da Presidente Dilma Rousseff como um golpe parlamentar ${ }^{2}$ ), o então governo impôs reforma para - Ensino Médio através de Medida Provisória (MP) de forma autoritária, marcada pela ausência de diálogo com os profissionais da educação e com a sociedade brasileira em geral. O caráter impositivo da medida é confirmado quando analisamos o artigo $62^{3}$ da Constituição Federal que determina que as MPs só deveriam ser implementadas "em caso de relevância e urgência" ${ }^{4}$ (BRASIL, 1988, p. 1), o que atesta o caráter antidemocrático da reforma.

Podemos afirmar que em contextos sociais e políticos conturbados, marcados pela tomada de poder nas circunstâncias acima descritas, a implantação imediata de reformas no contexto educacional configura-se como historicamente recorrente, "assim foi na ditadura Vargas, na ditadura empresarial-militar de 1964, no golpe neoliberal na década de 1990 à Constituição Federal e, agora, no golpe parlamentar, midiático, jurídico e policial" (MOTTA; FRIGOTTO, 2017, p. 367).

Sobre a natureza da reforma, conforme declarou a Exposição de Motivos da MP 746/2016, o atual governo "alinha as premissas da presente proposta às recomendações do Banco Mundial e do Fundo das Nações Unidas para Infância - Unicef" (BRASIL, 2016, p. 10), órgãos que historicamente impuseram propostas curriculares visando atender prioritariamente às demandas do mercado de trabalho, desvinculadas de uma efetiva formação humana e integral dos estudantes.

Diante do posicionamento autoritário do Governo, questionando os interesses da atual proposta formatada para o Ensino Médio, diversos setores da sociedade civil apresentaram-se radicalmente contra a proposta de reforma, dentre os quais se destacou o Movimento Nacional em Defesa do Ensino Médio ${ }^{5}$, assim como o movimento dos estudantes secundaristas, que

2 Ilustrando a compreensão do impeachment enquanto golpe parlamentar, destacamos Guilherme (2017).

${ }^{3}$ Cuja redação foi dada pela Emenda Constitucional no 32, de 2001.

4 "A Medida Provisória (MP) é um instrumento com força de lei, adotado pelo presidente da República, em casos de relevância e urgência. Produz efeitos imediatos, mas depende de aprovação do Congresso Nacional para transformação definitiva em lei" (CÂMARA DOS DEPUTADOS, 2017. Disponível em: <http://www2.camara.leg.br/comunicacao/assessoria-deimprensa/medida-provisoria>. Acesso em: 28/08/2017).

${ }^{5}$ Movimento composto pelas seguintes entidades: Associação Nacional de Pós-graduação e Pesquisa em Educação (ANPEd), Centro de Estudos Educação e Sociedade (CEDES), Fórum Nacional de Diretores das Faculdades de Educação (FORUMDIR), Associação Nacional pela Formação dos Profissionais da Educação (ANFOPE), Campanha Nacional pelo Direito à Educação, Ação Educativa, Associação Nacional de Política e Administração da 
promoveu a ocupação de mais de 1100 escolas em 22 estados brasileiros. llustrando a perspectiva contrária à reforma, destacamos o posicionamento da Associação Brasileira de Educação Musical indicando que "uma ação dessa natureza, excludente e unilateral, é um desrespeito a alunos, professores, pais, estudiosos da educação e a toda sociedade do país que vêm, ao longo das últimas décadas, consolidando avanços significativos para a educação básica"”.

\section{LEI № 13.415/2017}

Apesar do enfrentamento da sociedade civil, após quatro meses de tramitação, a proposta do governo foi aprovada integralmente na Comissão Mista incumbida de apreciá-la. Posteriormente foi convertida no Projeto de Lei no 34/2016, aprovado na Câmara dos Deputados e no Senado Federal e, finalmente, sancionada como Lei no 13.415 em 16 de fevereiro de 2017, passando a compor, portanto, a Lei de Diretrizes e Bases da Educação Nacional (Lei no 9.394/1996).

Analisando o caráter da reforma e traçando um paralelo da sua proposta com a proposta educacional trazida na década de 1990 por documentos como o Decreto n 2208/97, Kuenzer (2017, p. 339) reflete que "não obstante o esforço dos movimentos sociais organizados contra o então PL 1603/96 que subsidiou o Decreto n 2208/97, a política proposta pelo Banco Mundial renasce na Lei no 13.415/2017, autoritária tanto na forma quanto no conteúdo, orientado pela flexibilização". Desse modo, alterando de forma impositiva a LDB 9.394/1996, a Lei no 13.415/2017 pretende "modernizar" a estrutura curricular do Ensino Médio, flexibilizando-a por áreas de conhecimento, sob as justificativas de atender aos distintos projetos de vida dos jovens, assim como melhorar os resultados do desempenho escolar brasileiro.

As justificativas para a proposta da reforma curricular agrupam-se em torno basicamente dos seguintes pontos: o baixo desempenho dos estudantes em Língua Portuguesa e Matemática, conforme o Índice de Desenvolvimento da Educação Básica (IDEB); a estrutura curricular que, compreendendo 13 disciplinas, foi considerada excessiva e seria a responsável pelo desinteresse e fraco desempenho dos estudantes e; a necessidade de modernização, no sentido de flexibilizar o currículo por áreas

\footnotetext{
Educação (ANPAE), Conselho Nacional das Instituições da Rede Federal de Educação Profissional Científica e Tecnológica (CONIF), Associação Nacional de Pesquisa em Financiamento da Educação (FINEDUCA) e Confederação Nacional dos Trabalhadores em Educação (CNTE).

6 Nota pública da ABEM sobre a Medida Provisória № 746 que altera Ensino Médio. Disponível em: <http://www.abemeducacaomusical.com.br/artsg.asp?id=138>. Acesso em: 07/10/2017.
} 
de conhecimento, voltando-se para as aptidões dos alunos e das unidades escolares.

Defendendo os pontos destacados, o então Ministro da Educação, Mendonça Filho, compreende que "esse atual modelo, com 13 disciplinas obrigatórias, expulsa os jovens do ensino médio no Brasil" (BRASIL, 2017d, $\mathrm{s} / \mathrm{p}$ ). O ministro ainda destacou que "quase 2 milhões deles estão fora das escolas, e o Brasil não atinge a meta do ldeb para o ensino médio desde 2011". Analisando os referidos argumentos, Motta e Frigotto (2017, p. 365) refletem que:

É nessa seara que a reestruturação do currículo do Ensino Médio é posta como urgente: melhorar o desempenho no IDEB e no PISA, flexibilizando o currículo de forma a facilitar as escolhas das disciplinas que os jovens das classes populares teriam menor dificuldade e, com isso, provavelmente, melhor desempenho nas avaliações em larga escala; desenvolver habilidades e competências que facilitem o ingresso no mercado de trabalho, formal ou informal, ou que proporcionem ocupações que venham a gerar renda nesse caso, por meio do ensino de empreendedorismo. (MOTTA; FRIGOTTO, 2017, p. 365).

$\mathrm{Na}$ visão dos reformadores, a modernização do currículo do Ensino Médio busca alterar o currículo sobrecarregado de disciplinas "desinteressantes" e/ou "inúteis", portanto, pouco atraentes aos jovens. Disciplinas tais quais educação física, arte, geografia, história, sociologia e filosofia - todas estas diretamente relacionadas com a formação humana dos sujeitos. O foco passa a ser então nas disciplinas que se relacionam mais diretamente com os conhecimentos demandados pelo mercado de trabalho (português, inglês e matemática), explicitando claramente o caráter tecnicista da proposta. Analisando esta conjuntura, Ferreira (2017) argumenta que:

[...] a contrarreforma ${ }^{7}$ do ensino médio é parte integrante de uma agenda globalmente estruturada da educação. Os exemplos utilizados pelos defensores dessas mudanças são frágeis, mas confirmam os padrões de governança internacional, cuja missão modernizadora é reduzir a educação (e o conhecimento) a funções mínimas de acordo com as necessidades imediatas da sociedade capitalista contemporânea. (FERREIRA, 2017, p. 304).

\footnotetext{
${ }^{7}$ A autora utiliza a expressão "contrarreforma" indicando que "a análise desenvolvida defende que se trata de uma contrarreforma, tal como defendido por Behring (2003), quando estudou o profundo retrocesso das políticas sociais ocorrido na década de 1990. Naquela ocasião, a autora se recusou a vincular o conceito de reforma a processos regressivos, pois esse conceito faz parte do debate do movimento operário, como uma estratégia revolucionária" (FERREIRA, 2017, p. 294).
} 
Em sua nova configuração, o currículo passa a ser dividido em duas partes, sendo "composto pela Base Nacional Comum Curricular [BNCC - que é comum a todos os estudantes] $]^{8}$ e por itinerários formativos, que deverão ser organizados por meio da oferta de diferentes arranjos curriculares, conforme a relevância para o contexto local e a possibilidade dos sistemas de ensino" (BRASIL, 2017a, p. 1). Nesse contexto, apenas matemática, língua portuguesa e língua inglesa serão disciplinas obrigatórias nos três anos do currículo. Os conteúdos e práticas relativos à educação física, arte, sociologia e filosofia, conforme o art. 35-A acrescido na LDB, estarão presentes na BNCC porém sem a obrigatoriedade de configurarem disciplinas. A segunda parte do currículo apresenta-se como "flexível" porque teoricamente caracteriza-se como aquela a ser escolhida pelos estudantes, tendo sido batizada de "itinerários formativos". $\mathrm{O}$ art. $4^{\circ}$ da Lei ${ }^{0} 13.415 / 2017$, alterando 0 art. 36 da LDB 9.394/1996, elencou as seguintes possibilidades a serem escolhidas pelos estudantes:

I - linguagens e suas tecnologias;

II - matemática e suas tecnologias;

III - ciências da natureza e suas tecnologias;

IV - ciências humanas e sociais aplicadas;

$\mathrm{V}$ - formação técnica e profissional.

Sobre o desenvolvimento das possibilidades indicadas, conforme mencionado anteriormente, $\mathrm{o}$ art. $4^{\circ}$ da Lei 13.415/2017 indica que estes itinerários serão ofertados a partir da "relevância para o contexto local" e da "possibilidade dos sistemas de ensino". Desse modo, o documento não determina a obrigatoriedade de oferta de mais de um itinerário formativo em nenhuma escola brasileira. Tendo em vista as condições materiais do sistema público educacional brasileiro, especialmente da Rede Estadual que atende prioritariamente ao Ensino Médio, concluímos que a "possibilidade de escolha" que supostamente seria concedida aos jovens estudantes não será materializada na maior parte dos estabelecimentos públicos brasileiros. Corroborando com este entendimento, Kuenzer (2017, p. 335) assinala que "a

\footnotetext{
8 "A Base estabelece conteúdos e competências essenciais, isto é, o que todo estudante deve saber e ser capaz de fazer na Educação Básica. Uma vez aprovada pelo CNE e homologada pelo ministro, será referência obrigatória na elaboração dos currículos de escolas públicas e particulares, em todo o Brasil”. Em abril de 2017, o MEC entregou a versão final da BNCC referente à Educação Infantil (creche e pré-escola) e ao Ensino Fundamental ( $1^{\circ}$ ao $9^{\circ}$ ano) ao Conselho Nacional de Educação (CNE) que irá, por sua vez, elaborar parecer e projeto de resolução que retornarão ao MEC. A BNCC referente ao Ensino Médio será entregue ainda em 2017, adaptada às novas diretrizes do "Novo Ensino Médio". "A partir da homologação da BNCC começa o processo de formação e capacitação dos professores e o apoio aos sistemas de Educação estaduais e municipais para a elaboração e adequação dos currículos escolares". Informações disponibilizadas pelo MEC através do endereço: <http://basenacionalcomum.mec.gov.br/>. Acesso em: 30/08/2017.
} 
oferta de quantos e quais itinerários formativos será definida pelos sistemas de ensino, segundo suas condições concretas, o que levará à restrição das possibilidades de escolha pelo aluno, ou seja, ao enrijecimento". A partir desse argumento, compreendemos como equivocada e mal-intencionada a fala do ex-Ministro da Educação, Mendonça Filho, ao afirmar que "o texto [da reforma] dá autonomia e protagonismo ao jovem como um mecanismo para manter os estudantes na escola" (BRASIL, 2017d, s/p).

Ainda analisando os efeitos dos itinerários formativos, Kuenzer (2017, p. 335) aponta que "todos os certificados habilitam à continuidade de estudos no ensino superior, contudo o itinerário cursado reduz as possibilidades de sucesso em processos seletivos para áreas diferentes da cursada, o que levará os alunos a frequentarem cursos preparatórios [via de regra privados], que acabam sendo incentivados pela nova proposta". Refletindo acerca da natureza da flexibilização imposta, a autora traça um paralelo relacionando-a com a "pedagogia da acumulação flexível":

Em resumo, o ensino médio na atual versão integra a pedagogia da acumulação flexível e tem como finalidade a formação de trabalhadores com subjetividades flexíveis, por meio de uma base de educação geral complementada por itinerários formativos por área de conhecimento, incluindo a educação técnica e profissional; a formação profissional é disponibilizada de forma diferenciada por origem de classe, de modo a levar os que vivem do trabalho a exercer, e aceitar, de forma natural, as múltiplas tarefas no mercado flexibilizado. Ser multitarefa, neste caso, implica exercer trabalhos disponibilizados pelo mercado, para os quais seja suficiente um rápido treinamento, a partir de algum aporte de educação geral, seja no nível básico, técnico ou superior. (KUENZER, 2017, p. 341, grifos nossos).

Desse modo, a atual reforma retoma os objetivos de propostas implantadas no Brasil no contexto da década de 1990, como a proposta da "pedagogia das competências" "na qual a organização dos currículos assume "formatos flexíveis", abarcando possibilidades como, por exemplo, a viabilidade de "saídas intermediárias e finais, sempre que possível" (BRASIL, 2001, p. 4). Acerca das transformações ocorridas nos âmbitos social e político durante aquele contexto (anos de 1990), destacamos análise de Frigotto e Ciavatta (2011):

\footnotetext{
${ }^{9}$ Acerca do conceito de competência, destacamos, conforme Garcia (2013, p. 53), que, "além da separação da formação técnica do processo de escolarização, o conceito de competências, a partir do decreto $n^{\circ}$ 2208/97, adquiriu o sentido reduzido de competências para o mercado de trabalho e enfatizou a fragmentação do conhecimento".
} 
[...] na década de 1990, sob a base da mundialização do capital, das reformas que consubstanciam o desmanche do Estado na garantia de direitos coletivos e universais e do avassalador processo de privatizações, que a ideologia do capital humano se redefine, mediante as noções de sociedade do conhecimento, qualidade total, pedagogia das competências, empregabilidade e empreendedorismo. (FRIGOTTO; CIAVATTA, 2011, p. 624).

Confirmando a aproximação com o Decreto oㅡ 2.208/97, a partir da Lei 13.415/2017 a educação técnica e profissional poderá voltar a ser organizada em módulos com sistema de créditos e terminalidade específica, possibilitando novamente as "saídas intermediárias". Desse modo, é retomada "a possibilidade de concessão de certificados intermediários de qualificação para o trabalho, quando a formação for estruturada e organizada em etapas com terminalidade" (BRASIL, 2017a, p. 1).

Acerca dessa organização curricular demasiadamente fragmentada, caracterizada pelas saídas intermediárias, concordamos com autores tais quais Moura e colaboradores (2012, p. 219) que apontam para uma precarização da formação, que "enfatiza a centralidade da educação profissional na dimensão econômica, tomando o mercado como instrumento regulador da sociabilidade humana".

Outro ponto abordado na reforma diz respeito à possibilidade de contratação de "especialistas", não-licenciados, para atuação como professores no quinto eixo do dos itinerários formativos, referente à formação técnica e profissional. Segundo a Lei no 13.415/2017, conforme seu Art. 6o (que altera o Art. 61 da LDB), consideram-se profissionais da educação escolar básica, para atuação na formação técnica e profissional, "profissionais com notório saber reconhecido pelos respectivos sistemas de ensino, para ministrar conteúdos de áreas afins à sua formação ou experiência profissional, atestados por titulação específica ou prática de ensino em unidades educacionais da rede pública ou privada ou das corporações privadas em que tenham atuado" (BRASIL, 2017a, p. 1).

A partir dos argumentos expostos, concordamos com Motta e Frigotto (2017, p. 357) que "se trata de uma reforma contra os filhos da classe trabalhadora, negando-lhes o conhecimento necessário ao trabalho complexo e à autonomia de pensamento para lutar por seus direitos". Na atual conjuntura, fica explícito que as classes dominantes utilizam-se do Estado como mecanismo de controle social, através dos instrumentos voltados à regulação da educação destinada à formação dos trabalhadores. Sobre essa questão, Motta e Frigotto (2017) refletem que:

O momento brasileiro é de uma crise aguda que insere medidas econômicas e políticas ofensivas que afetam 
fundamentalmente nossos muitos milhares de jovens da classe trabalhadora. E as Jornadas de Junho e as ocupações das escolas e universidades públicas indicam que irrompeu a luta de classes. Com isso, as burguesias dominantes asseveram os mecanismos de controle social por meio dos vários aparelhos do Estado em "união pessoal" com seus respectivos aparelhos privados de hegemonia e com organismos internacionais, introduzem um conjunto de políticas públicas que conformam a conjuntura [...] e buscam cimentar a ideologia necessária para se consolidarem no poder e salvaguardarem os ganhos do capital. Por esse motivo, torna-se determinante introduzir reformas na educação - ressaltamos, pública — na qual se situa a grande massa de jovens da classe trabalhadora para administrar a "questão social" e criar as condições favoráveis para a expansão do capital. (MOTTA; FRIGOTTO, 2017, p. 365).

Desse modo, a atual proposta de reforma retroage a diversas questões que supostamente haviam sido "superadas" na trajetória da educação profissional brasileira. Dentre os retrocessos impostos, podemos destacar, por exemplo, a aproximação com a Reforma Capanema no contexto da ditadura Vargas, onde o ensino secundário industrial, comercial e agrícola não possuía equivalência para o ingresso no Ensino Superior. No atual contexto, sob a justificativa que os estudantes devem possuir "alternativas de escolha", a Lei no 13.415/2017 criou cinco itinerários estanques que supostamente serão ofertados pelas escolas. Na prática, tais itinerários apesar de formalmente equivalentes, restringirão a entrada no Ensino Superior de acordo com os conhecimentos específicos adquiridos em cada área de formação. Corroborando com esta análise, destacamos a reflexão de Cunha (2017):

Se atentarmos para a articulação com os cursos superiores, veremos que essa discriminação assumirá uma configuração especial. Na prática, e na melhor das hipóteses, para os egressos da Formação Técnica e Profissional restarão os cursos tecnológicos, mais curtos e específicos; para os demais, cursos profissionais plenos e os bacharelados interdisciplinares. Pode-se divisar uma correspondência com a formatação da educação brasileira na legislação concebida por Gustavo Capanema durante o Estado Novo. (CUNHA, 2017, p. 379)

Podemos apontar ainda que a proposta da reforma, conforme analisam Motta e Frigotto, (2017, p. 368), "retroage à Lei $n^{\circ} 5.692 / 1971$, reforma da educação dos tempos da ditadura empresarial militar com uma profissionalização precária frente às realidades dos estados". Tal argumento 
baseia-se nas condições concretas da realidade brasileira, visto que a escolha pelos itinerários formativos não irá configurar uma questão de "livre escolha", como indicam os reformadores, mas compulsória, pois depende efetivamente das condições infraestruturais das escolas públicas brasileiras situação idêntica àquela promovida pela Lei $n^{\circ}$ 5.692/1971. "Nessas condições dadas, cada escola vai ofertar a educação profissional que couber em seu orçamento" (MOTTA; FRIGOTTO, 2017, p. 368).

\section{IMPLANTAÇÃO DO MEDIOTEC}

Confirmando a análise realizada em torno do retrocesso imposto pela contra-reforma do Ensino Médio através da Lei no 13.415/2017, retomando explicitamente a intensificação da dualidade estrutural entre educação profissional e educação básica, o Ministério da Educação iniciou a implantação do programa "MedioTec" para o segundo semestre de 2017, sendo este a incorporação do Pronatec no Ensino Médio regular. Diferenciando-se da proposta de Educação Técnica Integrada do Ensino Médio, voltada essencialmente para a formação integral (omnilateral) dos estudantes ${ }^{10}$, o programa aproxima-se da forma "concomitante" de educação profissional, pois as formações oferecidas por meio do MedioTec são realizadas simultaneamente ao Ensino Médio regular, vinculando o estudante à duas matrículas (uma do Ensino Médio e outra do Ensino Técnico) e, ao final, dois certificados de conclusão. O programa vem sendo executado em parceria com instituições públicas e privadas de Ensino Médio.

Conforme ressaltou o Ministério da Educação, "o MedioTec surge como um braço do Programa Nacional de Acesso ao Ensino Técnico e Emprego (Pronatec), visando a acelerar o processo de mudanças previsto na reforma do ensino médio e vai ser em um esquema concomitante de aulas em tempo integral com a educação técnica" (BRASIL, 2017b, s/p). Ainda conforme o Ministério, o MedioTec "permite aos estudantes terminarem o ensino médio com um pé no mercado de trabalho" (BRASIL, 2017b, s/p). Explicitando a redução da carga horária imposta pelo programa - assim como a ênfase tecnicista que resumiu basicamente o currículo em língua portuguesa, matemática e conhecimentos básicos para a execução de ofícios no mercado de trabalho -, o Documento de referência de execução para todas as redes ofertantes indica que:

Hoje, se o jovem quiser cursar uma formação técnica de nível médio, ele precisa cursar 2400 horas do ensino médio regular e mais 1000 ou 1200 horas do técnico. O Novo Ensino Médio

\footnotetext{
${ }^{10}$ Para uma maior compreensão acerca da proposta formativa do Currículo Integrado, consultar Ramos (2008).
} 
permitirá que o jovem opte por uma formação técnica profissional dentro da carga horária do Ensino Médio regular desde que ele continue cursando português e matemática até o final. (BRASIL, 2017c, p. 5)

Com o objetivo de atender às demandas advindas do mercado de trabalho, a então secretária de Educação Profissional e Tecnológica (Setec) do MEC, Eline Nascimento indica que:

[...] a oferta dos cursos tem como base um mapeamento de empregabilidade a longo prazo e leva em consideração características e potencialidades de mercados locais. "As vagas que ofertamos estão de acordo com o mapa elaborado pelos ministérios, que mostra as demandas do mercado quando essas turmas concluírem", disse [a secretária]. (BRASIL, 2017b, s/p)

É importante ressaltar que o MedioTec pretende estimular parcerias entre as instituições ofertantes e as empresas da região visando a absorção dos estudantes ainda na condição de aprendizes ou estagiários durante a realização do curso. Caracterizando a submissão do programa ao mercado de trabalho, ainda na fala da secretária Eline Neves Braga, "o foco [do programa] será o ensino médio porque o índice de desemprego no Brasil é maior entre os jovens, mas vamos direcionar as vagas para os cursos de acordo com as necessidades de mercado" (BRASIL, 2017b, s/p). Acerca da lista de quais habilitações (cursos) serão ofertadas, indicando a prioridade dada às necessidades do mercado, a secretária executiva do MEC, Maria Helena Guimarães, salientou que, "pelo MedioTec o mercado de trabalho é que vai servir de parâmetro para essa definição" (BRASIL, 2017b, s/p).

Explicitando a vinculação direta entre o programa e a nova proposta do Ensino Médio, o Guia MedioTec (BRASIL, 2017d, p. 7) ressalta a possibilidade apontada pela Portaria do MEC $n^{0} 817$, de 13 de agosto de 2015, indicando que "os cursos a serem ofertados [pelo PRONATEC] poderão compor itinerários formativos que possibilitem o aproveitamento contínuo e articulado dos estudos, conforme previsto no Decreto no 5.154, de 2004". Desse modo, compreendemos que o eixo de formação profissional introduzido dentro dos "itinerários formativos" presentes no atual Ensino Médio poderá ser desenvolvido a partir das atividades do MedioTec, o que explicita a total precarização imposta pela reforma.

A partir das questões apontadas envolvendo o contexto da reforma imposta para o Ensino Médio, compartilhamos com Motta e Frigotto (2017, p. 368) a análise de que se trata de "uma contrarreforma destinada aos filhos da classe trabalhadora. Também uma confissão explícita de que o MEC assume, 
de fato, uma divisão classista da educação". Ainda nessa perspectiva, os autores apontam:

A conclusão clara é que a contrarreforma do Ensino Médio por imposição autoritária de MP é congruente e necessária para sustentar violência da PEC $n^{\circ}=55$, que expressa o desmanche dos direitos universais da classe trabalhadora mediante o congelamento dos recursos públicos para a educação, saúde, cultura, etc. "Reforma" que traduz, na prática, o ideário liberal-conservador no qual convergem elementos fascistas do movimento Escola "sem" Partido e economicistas do Todos pela Educação, revestidos pelas benesses da filantropia dos homens de bem e propulsores do desenvolvimento econômico. (MOTTA; FRIGOTTO, 2017, p. 368)

Conforme ressaltaram Motta e Frigotto, a reforma do Ensino Médio (da qual o MedioTec faz parte) inseriu-se no contexto mais amplo da gestão do presidente Michel Temer, dentro do qual devemos destacar o Projeto de Emenda Constitucional (PEC) 55 que, aprovada em dezembro de 2016, congelou por 20 anos os gastos públicos nas esferas sociais (educação e saúde). De acordo com a medida, o orçamento disponível para gastos será o mesmo do ano anterior acrescido apenas da inflação daquele ano. Desse modo, os investimentos nas duas áreas, que já não dão conta efetivamente das demandas sociais, desconsiderarão inclusive o crescimento populacional das próximas duas décadas. Podemos afirmar que se trata da maior mudança em matéria fiscal desde a Constituição de 1988. Realizando análise da PEC 55, Motta e Frigotto (2017) apontam que:

A PEC no 55, aprovada no Congresso Nacional, representa, sem dúvida, as forças sociais que golpearam a democracia brasileira e constitui-se na maior agressão às conquistas de direitos da classe trabalhadora desde o fim da escravidão. Liquida o Estado brasileiro como agente de garantia de direitos universais, dos quais se destacam o trabalho, a educação, a saúde e a habitação. Uma medida que confirma os argumentos da "urgência" da reforma do Ensino Médio, pois não só o inviabiliza como educação básica de qualidade, como o privatiza por dentro. Assim como vai acabar de privatizar, por mecanismos diversos, as universidades públicas. (MOTTA; FRIGOTTO, 2017, p. 366)

Estagnando por 20 anos o investimento público na área social, "o governo reserva toda a riqueza produzida para ganhos do capital, em especial mediante juros criminosos acobertados por leis injustas. Leis e Justiça têm caminhado em sentido oposto aos interesses da classe 
trabalhadora e de forma aberta" (MOTTA; FRIGOTTO, 2017, p. 366). Desse modo, a PEC 55 caracteriza um pacote de austeridade efetivamente elaborado para o retrocesso social, impactando especialmente as condições de vida da parcela mais pobre da população brasileira.

\section{CONSIDERAÇÕES FINAIS}

Como conclusão, podemos afirmar que a contra-reforma do Ensino Médio legitima o projeto social da classe dominante brasileira que, em sua base político-econômica, condena as próximas gerações das camadas populares ao trabalho simples e "nega os fundamentos das ciências que permitem aos jovens entender e dominar como funciona o mundo das coisas e a sociedade humana" (MOTTA; FRIGOTTO, 2017, p. 369). Assim, o atual contexto sócio-político no qual se inserem a PEC 55 e a reforma do Ensino Médio inevitavelmente vai agravar a desigualdade social (sendo esta a principal característica socioeconômica brasileira), comprometendo o futuro dos filhos da classe trabalhadora por meio de um novo ciclo marcado pela intensificação da dualidade estrutural (o que explicita o caráter cíclico dos avanços e retrocessos das políticas educacionais brasileiras).

Evidencia-se então, claramente, a disputa entre, por um lado, a lógica hegemônica, que prioriza o aspecto econômico, em detrimento do aspecto humano e social, e materializa um atendimento de acordo com a hierarquia social; e, por outro, a lógica humanística, que põe o indivíduo no centro das políticas públicas e entende a importância do aspecto econômico, mas sem colocá-lo como centro do processo político governamental.

\section{REFERÊNCIAS}

CERVO, A. L.; BERVIAN, P. A.; SILVA, R. da. Metodologia científica. 6. ed. São Paulo: Pearson Prentice Hall, 2007.

BRASIL. Constituição de 1988. Constituição da República Federativa do Brasil. In: Diário Oficial da União - Seção 1 - 5/10/1988, p. 1 (Publicação Original). 1988. Disponível em:

<http://www2.camara.leg.br/legin/fed/consti/1988/constituicao-1988-5-outubro1988-322142-publicacaooriginal-1-pl.html>. Acesso em: 26/07/2013. . Ministério da Educação. Parâmetros Curriculares Nacionais

(Ensino Médio): Parte I - Bases Legais. Brasília: MEC, 2000. Disponível em: $<$ http://portal.mec.gov.br/seb/arquivos/pdf/blegais.pdf>. Acesso em: 01/02/2013. . Ministério da Educação. Secretaria de Educação Média e 
Tecnológica. Orientações para a formulação e apresentação dos planos de cursos técnicos com base na Resolução CNE/CEB № 04/99. Brasília: MEC/SEMTEC/CGEP, 2001. Disponível em: $<$ http://portal.mec.gov.br/setec/arquivos/pdf/oriplantec.pdf>. Acesso em: 06/02/2013.

Medida Provisória no 746, de 22 de Setembro de 2016. Institui a Política de Fomento à Implementação de Escolas de Ensino Médio em Tempo Integral, altera a Lei oㅜ 9.394, de 20 de dezembro de 1996, que estabelece as diretrizes e bases da educação nacional, e a Lei no 11.494 de 20 de junho 2007, que regulamenta o Fundo de Manutenção e Desenvolvimento da Educação Básica e de Valorização dos Profissionais da Educação, e dá outras providências. Brasília: 2016. Disponível em: <http://www2.camara.leg.br/legin/fed/medpro/2016/medidaprovisoria-746-22setembro-2016-783654-publicacaooriginal-151123-pe.html>. Acesso em: 28/09/2016.

Leis, Decretos. Lei no 13.415, de 16 de Fevereiro de 2017. Altera as Leis nos 9.394, de 20 de dezembro de 1996, que estabelece as diretrizes e bases da educação nacional, e 11.494, de 20 de junho 2007, que regulamenta o Fundo de Manutenção e Desenvolvimento da Educação Básica e de Valorização dos Profissionais da Educação, a Consolidação das Leis do Trabalho - CLT, aprovada pelo Decreto-Lei oㅡ 5.452, de 1ํㅡㄹ de maio de 1943, e o Decreto-Lei oㅡ 236, de 28 de fevereiro de 1967; revoga a Lei oㅡ 11.161, de 5 de agosto de 2005; e institui a Política de Fomento à Implementação de Escolas de Ensino Médio em Tempo Integral. Diário Oficial da União - Seção 1 - 17/2/2017, p. 1 (Publicação Original). 2017a. Disponível em: <http://www2.camara.leg.br/legin/fed/lei/2017/lei-13415-16-fevereiro2017-784336-publicacaooriginal-152003-pl.html>. Acesso em: 29/08/2017.

Ministério da Educação. Portal On-Line. Notícias. 2017b.

Disponível em: <http://portal.mec.gov.br/component/tags/tag/41151>. Acesso em: 03/09/2017.

. Ministério da Educação. Documento de referência de execução para todas as redes ofertantes [do MedioTec]. 2017c. Disponível em: <http://portal.mec.gov.br/index.php?option=com_docman\&view=download\&ali as=64881-documento-de-referencia-mediotec-pdf\&category_slug=maio-2017pdf\&ltemid=30192 $>$. Acesso em: 07/09/2017.

. Ministério da Educação. Guia MedioTec. 2017d. Disponível em: <http://portal.mec.gov.br/index.php?option=com_docman\&view=download\&ali as=64871-guia-meiotec-2017-pdf\&category_slug=maio-2017pdf\&ltemid=30192>. Acesso em: 03/09/2017.

Ensino Médio: atalho para o passado. Educação \& Sociedade, Campinas/SP, v. 38, n. 139, abr./jun. 2017. Disponível em: <http://www.scielo.br/pdf/es/v38n139/1678-4626-es-38-139-00373.pdf>. Acesso em: 24/08/2017. 
CUNHA, Luiz Antônio. Ensino Médio: atalho para o passado. Educação \& Sociedade, Campinas/SP, v. 38, n. 139, abr./jun. 2017. Disponível em: <http://www.scielo.br/pdf/es/v38n139/1678-4626-es-38-139-00373.pdf>. Acesso em: 24/08/2017.

FERREIRA, Eliza Bartolozzi. A contrarreforma do Ensino Médio no contexto da nova ordem e progresso. Educação \& Sociedade, Campinas/SP, v. 38, n. 139, abr./jun. 2017. Disponível em:

<http://www.scielo.br/pdf/es/v38n139/1678-4626-es-38-139-00293.pdf>. Acesso em: 24/08/2017.

FRIGOTTO, Gaudêncio; CIAVATTA, Maria Aparecida; RAMOS, Marise Nogueira. (Orgs.). Ensino médio integrado: concepção e contradições. São Paulo: Cortez, 2005.

FRIGOTTO, Gaudêncio; CIAVATTA, Maria Aparecida. Perspectivas sociais e políticas da formação de nível médio: avanços e entraves nas suas modalidades. Educação \& Sociedade, Campinas/SP, v. 32, n. 116, p. 619638, jul./set. 2011. Disponível em:

<http://www.scielo.br/pdf/es/v32n116/a02v32n116.pdf>. Acesso em: 20/04/2017.

GARCIA, Sandra Regina de Oliveira. Ensino Médio e Educação Profissional: breve histórico a partir da LDBEN no 9394/96. In: AZEVEDO, Jose Clovis de; REIS, Jonas Tarcísio. Reestruturação do ensino médio: pressupostos teóricos e desafios da prática. São Paulo: Fundação Santillana, 2013. p. 4964.

GUILHERME, Cássio Augusto. De Dilma a Temer: da crise do lulismo ao golpe do pemedebismo. In: SIMPÓSIO NACIONAL DE HISTÓRIA, 29., 2017, Brasília/DF. Anais... Brasília/DF: Universidade de Brasília, 2017. Disponível em:

<http://www.snh2017.anpuh.org/resources/anais/54/1502040383_ARQUIVO_ Artigocompleto-Anpuh2017-deDilmaaTemer.pdf>. Acesso em: 20/09/2017.

KUENZER, Acácia Zeneida. Trabalho e escola: a flexibilização do Ensino Médio no contexto do regime de acumulação flexível. Educação \& Sociedade, Campinas/SP, v. 38, n. 139, abr./jun. 2017. Disponível em: <http://www.scielo.br/pdf/es/v38n139/1678-4626-es-38-139-00331.pdf>. Acesso em: 24/08/2017.

MEDEIROS, Valéria Matos Leitão; LEITE, Jocileide Bidô Carvalho; PEREIRA, Maria Zuleide da Costa. Trajetória histórica das políticas curriculares da Educação Profissional Técnica de Nível médio no Brasil. Trabalho \& Educação, Belo Horizonte, v. 22, n. 2, p.137-153, mai./ago. 2013. Disponível em: <http://www.portal.fae.ufmg.br/seer/index.php/trabedu/article/view/1320>. Acesso em: 20/10/2013.

MOTTA, Vânia Cardoso da; FRIGOTTO, Gaudêncio. Por que a urgência da reforma do Ensino Médio? Medida Provisória nº 746/2016 (Lei nº 
13.415/2017). Educação \& Sociedade, Campinas/SP, v. 38, n. 139, abr./jun. 2017. Disponível em: <http://www.scielo.br/pdf/es/v38n139/1678-4626-es-38139-00355.pdf>. Acesso em: 24/08/2017.

MOURA, Dante Henrique. Educação básica e educação profissional e tecnológica: dualidade histórica e perspectivas de integração. Holos, Natal, ano 23, v. 2, 2007. Disponível em:

<http://www2.ifrn.edu.br/ojs/index.php/HOLOS/article/view/11>. Acesso em: 19/07/2013.

. Ensino médio integrado: subsunção aos interesses do capital ou travessia para a formação humana integral? Educação e Pesquisa, São Paulo, v. 39, n. 3, p. 705-720, jul./set. 2013a. Disponível em: <http://www.scielo.br/pdf/ep/v39n3/10.pdf>. Acesso em: 20/10/2013.

MOURA, Dante Henrique et al. Carta encaminhada ao Presidente da Câmara de Educação Básica do Conselho Nacional de Educação Brasília. Revista Brasileira de Educação, Rio de Janeiro, v. 17, n. 49, p. 219222, jan./abr. 2012. Disponível em: <http://www.scielo.br/pdf/rbedu/v17n49/a11v17n49.pdf>. Acesso em: 10/10/2013.

MOURA, Dante Henrique et al. Carta encaminhada ao Presidente da Câmara de Educação Básica do Conselho Nacional de Educação Brasília. Revista Brasileira de Educação, Rio de Janeiro, v. 17, n. 49, p. 219222, jan./abr. 2012. Disponível em: <http://www.scielo.br/pdf/rbedu/v17n49/a11v17n49.pdf>. Acesso em: 10/10/2013.

RAMOS, Marise Nogueira. Concepção do Ensino Médio Integrado. In: SEMINÁRIO ENSINO MÉDIO DA SECRETARIA DE EDUCAÇÃO DO ESTADO DO PARANÁ, 1., Paraná, 2008. Anais... Belém: Secretaria de Educação do Estado do Paraná, 2008. Disponível em:

<http://forumeja.org.br/go/sites/forumeja.org.br.go/files/concepcao_do_ensino _medio_integrado5.pdf>. Acesso em: 14 fev. 2018. 